EL PAPEL SIMBÓLICO

\section{DE LA TIPOGRAFíA EN}

\section{LOS NUEVOS DISPOSITIVOS}

MÓVILES

\section{Hacia la reconciliación}

\section{de letras y pantallas}

\section{Blas José Subiela Hernández}

Doctor en comunicación

Universidad Católica San Antonio de Murcia, Campus de los Jerónimos, s/n, 30107 Guadalupe, Murcia (España) - Email: bsubiela@ucam.edu

\section{Resumen}

Este artículo analiza el uso simbólico de la tipografía en los nuevos soportes electrónicos de lectura, en un momento en el que la tecnología hace a las pantallas cada vez más competitivas frente al papel impreso.

En primer lugar, se presenta una recopilación de los significados simbólicos que se han asociado a las principales categorías tipográficas en la cultura occidental a lo largo de los siglos. Con ello se pretende recordar y reivindicar el papel simbólico de la tipografía.

A continuación, se estudia el fenómeno del libro electrónico y de los diferentes dispositivos utilizados para su lectura
Palabras clave

Retórica, tipografía, simbolismo, lectura electrónica, ebook, resolución, pantallas

Key Words

Rhetorics, typography, siymbolism, electronic reading, ebook, resolution, screens

\section{Abstract}

This article analyzes the symbolic use of typography in the new elec-

tronic devices in a time when technology makes screens more and more competitive compared to print.

First of all, we present a collection of symbolic meanings that are associated with the main typographic categories in Western culture over the centuries, to remember and to vindicate the symbolic role of typography.

Next, we approach the phenomenon of e-book and the different devices used for reading from a technical point of view, analyzing the prob-

lems that have traditionally been associated to reading in screens and also addressing the latest technological advances.

Finally, confronts a content analysis, comparing a paper book with its digital equivalent. This analysis and the review of scientific literature and newspaper, allow us to develop a precise state of the question, from which we conclude that, despite the new opportunities offered by technology, typography symbolism remains underused in electronic devices. 
desde un punto de vista técnico, analizando los inconvenientes que tradicionalmente ha tenido la lectura en pantallas y abordando también los últimos avances tecnológicos.

Por último, se afronta un análisis de contenido comparando un libro en papel con su equivalente electrónico. Este estudio de caso, junto con la revisión de fuentes hemerográficas y bibliográficas nos ha permitido elaborar un estado de la cuestión a partir del cual podemos concluir que, a pesar de las nuevas posibilidades que brinda la tecnología, el simbolismo tipográfico no se puede explotar en los libros electrónicos de una forma similar a como se hace en los de papel. De hecho, observamos el desarrollo de un lenguaje tipográfico propio de este nuevo soporte de lectura.

\section{Introducción}

El objeto de esta investigación es el simbolismo tipográfico en los textos electrónicos. A lo largo de la historia de la tipografía se han desarrollado distintos diseños tipográficos que han representado épocas y que se han asociado culturalmente a una serie de significados simbólicos que van más allá del significado lingüístico que contiene cada letra. El diseño editorial (libros, revistas, diarios, etc.) ha hecho uso de este simbolismo tipográfico en el soporte impreso a lo largo de los años. Sin embargo, en el soporte digital las posibilidades de la tipografía han sido limitadas por varios motivos, especialmente por la baja resolución de las pantallas (que impide una adecuada definición en los caracteres) y también por la imposibilidad de incorporar tipografías específicas en el diseño web (por lo que los diseñadores deben utilizar diseños comunes, que estén disponibles en los ordenadores de los usuarios).

Por lo tanto, este trabajo se puede enmarcar dentro de los estudios de la retórica de la imagen, y más concretamente, de la retórica de la tipografía, aunque debe mirar también especialmente hacia cuestiones de carácter técnico y tecnológico, en lo que se refiere a la evolución de las características de las pantallas electrónicas.

\section{Objetivos}

Este artículo pretende contestar la siguiente pregunta: ¿Los textos electrónicos, en la actualidad, aprovechan el simbolismo tipográfico de una forma tan amplia como los impresos? 
Para intentar dar respuesta a esta cuestión, en primer lugar nos planteamos el objetivo de realizar un catálogo con los significados simbólicos asociados a las principales categorías de diseños tipográficos, de modo que se recuerda y reivindica su utilización en los textos electrónicos.

También debemos fijarnos especialmente en las innovaciones técnicas que se han producido en los últimos años encaminadas a la mejora de la reproducción de los tipos en los dispositivos electrónicos. Partimos de la base de que la tecnología ha sido, durante décadas, poco eficaz a la hora de representar textos en pantalla de forma nítida y definida. Sin embargo, en la actualidad se han producido importantes avances que, por primera vez, permiten a las pantallas competir en condiciones similares con el papel impreso. Así, otro de nuestros objetivos es estudiar dichas innovaciones técnicas para comprobar si se traducen en una mejora de la función gráfica o simbólica de la tipografía en los textos electrónicos.

\section{Metodología}

La metodología empleada en este trabajo ha sido la revisión bibliográfica y hemerográfica, tanto de obras monográficas como de artículos científicos y de actualidad. Además, se ha realizado un análisis de contenido comparando la edición en papel de una novela con su equivalente en formato digital.

Si pretendemos analizar el simbolismo tipográfico en los libros electrónicos, lo primero que debemos hacer es recordar y reivindicar dicho simbolismo. En este sentido, realizamos una revisión bibliográfica de los monográficos más importantes publicados en España en la última década sobre tipografía, de modo que podemos ofrecer un "catálogo" (nunca excluyente y siempre incompleto) del simbolismo asociado histórica y culturalmente a las categorías tipográficas fundamentales. En los casos que proceda, se prestará especial atención a las particularidades de los diferentes diseños cuando se muestran en pantallas.

A continuación, esta investigación define los dispositivos móviles de lectura y diferencia claramente el fenómeno del libro electrónico de los diferentes soportes que sirven para su lectura. Una vez hecha esta diferencia, estudiamos la situación actual de estas tecnologías. Para ello recurrimos a artículos científicos, a investigaciones sectoriales de origen profesional y también a artículos periodísticos de 
actualidad, con el fin, precisamente, de dotar de la máxima novedad a nuestro trabajo. En este caso, la búsqueda hemerográfica se ha realizado a nivel internacional, por medio de la base de datos académica de EBSCO, limitando temporalmente los resultados a los últimos dos años. Además, también se han realizado entrevistas a profesionales del diseño editorial, que nos han permitido completar la perspectiva académica.

Para el análisis de contenido, realizaremos una comparación entre la edición en papel y la edición digital de La Historia Interminable (Michael
Ende, 1979). En concreto, utilizaremos el archivo en formato $e P U B$, el formato de libro electrónico más extendido en la actualidad, y como soporte de lectura recurrimos al Sony Reader (PRS-T1), uno de los dispositivos de gama alta más valorados en nuestro país.

Perseguimos de esta forma realizar un retrato fiel de lo que está ocurriendo con la tipografía en el universo digital, analizando avances y retos en lo que respecta, especialmente, a la utilización de los distintos diseños de tipos desde un punto de vista simbólico.

\section{Reivindicación del simbolismo tipográfico}

La tipografía no es solo transmisora de un significado lingüístico, sino que también transporta un significado gráfico al que no debemos renunciar, menos aún por razones tecnológicas. No podemos olvidar que la letra escrita es un signo semiótico cuyo significante -representación gráfica- puede adoptar muy distintas formas, mientras que su significado fundamental -significado lingüístico- permanecerá invariable. Sin embargo, las distintas formas en las que se represente gráficamente la letra pueden producir un significado que vaya más allá del estable signifi- cado lingüístico. Por eso, para Gamonal (2005):

Los caracteres pueden transmitir no sólo información textual, sino también múltiples emociones y sensaciones a través de su forma. La elección de un tipo de letra nunca es arbitraria y requiere un ejercicio de reflexión que siempre tiene en su punto de mira al lector-receptor y los conceptos e ideas que se le quieren transmitir.

Así pues, el valor simbólico de la tipografía procede, sobre todo, de la mor- 
fología propia de cada familia (caracteres duros, pesados, ligeros, etc.)

No obstante, el simbolismo de un diseño tipográfico no procede únicamente de sus formas sino también de las experiencias vitales que se han asociado a él. Por lo tanto, el recorrido que ahora iniciamos por el simbolismo de las distintas tipografías se basará en la morfología de cada una de las categorías que iremos estableciendo ${ }^{\mathrm{i}}$, aunque también tendremos en cuenta, cuando proceda, el simbolismo de origen social y cultural -nacido del uso- asociado a determinados diseños.

\subsection{El origen de la tipografía: góticas o de escritura}

En esta categoría agrupamos todas las tipografías que están más vinculadas en sus formas con la escritura manual o caligráfica que con los caracteres industriales de imprenta. De hecho, los primeros tipos de la historia -nacidos con el descubrimiento de la imprenta y los tipos móviles- pertenecen a esta categoría, ya que lo que se pretendía entonces era imitar por medios mecánicos el trabajo manuscrito de los copistas. Así ponen de manifiesto esta realidad Martín Montesinos y Mas Hurtana (2001: 51):

Los primeros móviles que se fundieron adoptaron las formas de la letra gótica. El mismo Gutenberg, lejos de cualquier ánimo de ruptura, sólo pretendía acelerar el interminable proceso que suponía, en aquel momento, la producción manuscrita de un libro.

Dentro de esta categoría podemos encontrar dos variedades bien diferenciadas: las caligráficas y las manuales.

Los primeros diseños de tipos metálicos corresponderían al grupo de las caligráficas, ya que imitan las formas moduladas y enlazadas de los textos escritos según un estilo normativo determinado. Familias como la Old English, clásicas y recargadas, o más delicadas como la Vivaldi, corresponden a este grupo. Son tipos muy apropiados para sugerir tradición, clasicismo, esmero o elegancia, ya que conectan con el cuidado y el orden clásico de la caligrafía manual. Según Loxley (2007: 22): "las asociaciones de la Old English son acogedoras, y evocan una idealizada Inglaterra medieval cuando en las tabernas locales servirían una pierna de venado con un jarro de aguamiel, mientras un juglar con medias rasgaba un laúd".

Las góticas caligráficas, por lo tanto, pueden transportarnos simbólicamente a diferentes contextos históricos: diseños como el ya citado o la Matura script, con sus rasgos gruesos y angulosos, remiten a la Edad Media y al 
trabajo de los amanuenses en los monasterios y abadías; mientras que fuentes como la Edwardian Script, caracterizadas por su delgadez y fluidez de trazos nos sugieren el universo romántico de la primera mitad del siglo XIX en Europa.

Sin embargo, algunos de estos diseños tipográficos generan asociaciones muy siniestras, al relacionarse estrechamente con el Tercer Reich de Hitler por el uso generalizado que de ellas se hizo en Alemania en esa época de la historia. Así lo reflejan Willberg y Forssman (2002: 12): "la gótica [...], un tipo de letra totalmente inocente, lleva todavía adherido, como un aire pestilente, el abuso que el nacionalsocialismo hizo de ella".

Las góticas manuales, por su parte, se caracterizan por su trazo libre, propio de una escritura manual no reglada, no caligráfica. Por tanto, son diseños más gestuales, que pueden llegar a transmitir cierto desenfado y dinamismo. Nos referimos a familias como, por ejemplo, la Brusch script. También todas las familias que imitan la caligrafía infantil, como la Comic sans, pertenecen a este grupo, aunque presentan un simbolismo más específico.

Todas las góticas son tipografías que se pueden utilizar también para mostrar el carácter subjetivo de un texto, a modo de refuerzo de la personalidad de su autor -como si fuese de su puño y letra. Cuando es este el objetivo, la elección de una caligráfica o una manual dependerá de los rasgos de la personalidad del autor que se pretendan destacar.

Se trata de una de las categorías que más dificultades ha presentado siempre para reproducirse en pantalla, debido a su gran modulación y a la profusión de pequeños detalles y serifas. Si la legibilidad de estos tipos es -en la actualidad-limitada en el papel, en pantallas se recomienda su uso únicamente para textos breves como titulares o rótulos.

\subsection{Los diseños más abundantes: romanas}

Las romanas son la evolución natural de las tipografías caligráficas de la categoría anterior. Conservan cierta modulación en el trazo, es decir, sus rasgos presentan diferentes grosores, como intentando conservar los efectos del plumín al dejar la tinta sobre el papel en los distintos ángulos de la escritura caligráfica. Y también tienen remates o serifas, es decir, pequeñas prolongaciones en los rasgos terminales, que si bien ya no actúan conectando físicamente unos caracteres con otros, como en las tipografías manuales, se pueden considerar una rémora de ellos. Son fruto de la influencia del Renacimiento en el campo del diseño tipográfico y nacen en Italia (de ahí el 
nombre de romanas) como alternativa renovadora frente a las góticas que llegaban desde Alemania (cuna de la imprenta y del diseño de tipos móviles).

Por lo tanto, los primeros diseños de caracteres romanos supusieron una auténtica revolución estética en el campo de la tipografía, ya que significaban dejar atrás el universo de la Edad Media y su oscurantismo, para abrazar un nuevo despertar cultural e intelectual. De algún modo, las tipografías romanas se convirtieron en uno de los símbolos importantes del cambio y de las ideas renovadoras. Así lo sospecha también Loxley (2007: 23), que opina que "tal vez la popularidad del estilo de las romanas se difundía a medida que se convertía en el sinónimo del cambio y de las nuevas ideas". Estaríamos, por tanto, ante el primer caso en el que un diseño tipográfico adquiere un significado que va más allá de su función meramente lingüística.

No obstante, si en el momento de su aparición las fuentes romanas supusieron una innovadora revolución, por lo que significaban de ruptura con las góticas que les precedían, en la actualidad no se pueden considerar, lógicamente, diseños innovadores o rupturistas. Sin embargo, sí conservan su carácter renacentista, en cuanto a su pro- porcionalidad, su sencillez y su elegancia clásica.

Dentro de la categoría de las romanas podemos diferenciar dos grupos: antiguas y modernas. Para las romanas antiguas es de aplicación todo lo expuesto hasta ahora sobre las romanas, ya que son ellas las que nacen en respuesta a las góticas medievales. Son diseños de este tipo fuentes como la Garamond, cuyo origen se remonta al siglo XVI o la Palatino, aunque la más representativa, sin duda, es la Times, creada por Stanley Morison para el diario norteamericano The Times en 1931 (Gürtler, 2005: 85). Por tanto, aunque las califiquemos de antiguas por su momento de aparición- el recorrido histórico de este tipo de fuentes llega a nuestros días, porque, a diferencia de las góticas, son fuentes totalmente vigentes en la actualidad. Su simbolismo estará ligado siempre a la corrección, la seriedad, la credibilidad, el rigor, cierto conservadurismo, etc.

Con respecto a las romanas modernas, son una evolución de las anteriores y se caracterizan por que la modulación se acentúa más aún y los remates se hacen también más sutiles, más finos. Uno de los ejemplos más representativos de este tipo de diseños es la Bodo$n i$. Las romanas modernas, con su delgadez y su sutil ornamentación, se asocian a la elegancia, a la sofistica- 
ción y también, de algún modo, a la innovación y la frescura, ya que la delgadez de algunos de sus trazos las convertían en fuentes casi "imposibles" para su lectura. Así pues, siguen siendo, incluso en la actualidad, las favoritas para las cabeceras y los titulares de revistas femeninas de moda de alta gama.

Las romanas modernas, a la hora de ser representadas en pantallas electrónicas, adolecen de problemas similares a los de las góticas por su gran modulación, difícil de lograr con nitidez en dispositivos de baja resolución. Sin embargo, las romanas antiguas, menos moduladas, son más compatibles con estos dispositivos.

\subsection{La demanda publicitaria: egipcias o tacudas}

Podemos considerar que las egipcias son letras que nacen exclusivamente con fines publicitarios. Son diseños que se desarrollan a principios del siglo XIX, coincidiendo con la industrialización de una gran parte de los países occidentales, y son tipos utilizados para hacer carteles y anuncios en prensa. Parece lógico que, en un momento histórico en el que cada vez hay más publicidad, surja la necesidad de que los anuncios se identifiquen como tales, para que llamen la atención del público, y para que se diferencien del contenido noticioso de los periódicos. Y una de las pocas formas de conseguir esto, es por medio de la creación de nuevos diseños tipográficos, que tengan un gran peso visual y que, por lo tanto, puedan llamar mucho la atención en textos breves. Se crean así nuevos diseños caracterizados por el grosor de sus trazos, la ausencia de modulación -o al menos una disminución de esta- y los remates rectangulares de anchura similar a la del resto de trazos. Para Martínez-Val (2002: 105), el origen de las egipcias también surge por necesidades comerciales: "poseían mucha mancha, eran fáciles de reproducir y de ajustar en los carteles, y además se veían desde muy lejos".

Solomon (1988: 69) justifica el nombre dado a esta categoría debido a la similitud entre algunos de sus rasgos y los jeroglíficos egipcios: "los pies en forma de bloques (de las nuevas tipografías egipcias) recordaban la rigidez de los antiguos jeroglíficos egipcios".

Lo cierto es que tuvieron un gran desarrollo como fuentes para textos breves de gran tamaño, que conseguían producir una mancha muy potente que atraía la atención del público hacía los anuncios. También son diseños con una gran apariencia mecánica, casi industrial, derivada de sus formas rectas y gruesas. Además, este simbolismo se refuerza a lo largo del siglo XX 
ya que la mayoría de máquinas de escribir mecánicas incorporaban juegos de caracteres de este tipo.

Uno de los ejemplos más claros de tipografía egipcia es la Rokwell, cuyas formas también pueden remitirnos al mundo universitario norteamericano. Y otro es la Courier, cuyo diseño imita al de las máquinas de escribir personales de las que hablábamos unas líneas más arriba. En este caso, fuentes con diseños de este tipo nos remiten al mundo del periodismo impreso de gran parte del siglo XX, a la investigación policíaca tan bien reflejada en el cine negro de los años 50, e incluso a los documentos oficiales de estado. De hecho, toda la documentación oficial del gobierno de EE.UU ha utilizado durante más de 20 años la fuente Courier como principal, hasta su sustitución por la Times a comienzos del año 2004 (Vanderbilt, 2004).

Aunque no son tipografías apropiadas para largos textos, sus trazos constantes y sus remates de gran anchura permiten que su reproducción en pantallas sea lo suficientemente clara como para no plantear problemas de legibilidad.

\subsection{La tipografía de \\ la tecnología: palo seco o sin serifas}

En esta categoría encontramos las familias tipográficas más alejadas de la escritura manual, ya que en ellas ha desaparecido toda modulación en el trazo y también se han eliminado todos los remates, incluso los más sutiles de las romanas. De modo que en esta categoría se encuentran las familias tipográficas de confección más moderna, con el mismo grosor en todos los trazos y sin ningún tipo de ornamentación.

Esta clase de tipografías tienen su origen a principios del siglo XIX, pero cuando se desarrollan realmente es en el periodo de entreguerras del XX, sobre todo a partir de la influencia de la Bauhaus y el funcionalismo. Este movimiento artístico aboga por la búsqueda de la "belleza útil", eliminando todo ornamento superfluo, y ello da como resultado, en el campo de la tipografía, la proliferación de nuevos diseños de palo seco. Ejemplo de esta fuerte influencia es la familia Bauhaus, o las primeras propuestas de la Futura, en las que la geometría y la simplicidad de las formas era excesiva, y ponía en peligro, tal y como reconoció el propio Paul Renner -autor del diseñola legibilidad de los textos así compuestos (Loxley, 2007: 163).

Son valores simbólicos propios de las tipografías de palo seco algunos como la funcionalidad, la técnica, la vanguardia, el dinamismo e incluso la juventud, ya que se pueden considerar 
opuestos al clasicismo de las romanas. Son tipografías mucho más arraigadas en los países centroeuropeos que en Inglaterra o los países mediterráneos, ya que su origen geográfico está, tal y como hemos dicho, fundamentalmente en Suiza y Alemania. Otro ejemplo de tipografía de Palo Seco muy característica, y cuyo nombre refuerza el origen centroeuropeo de estas fuentes es la Helvética. Se trata de un diseño suizo de los años 50 que se popularizó mucho en los 60. Según Simonson (2001) la Helvética:

Se convirtió en sinónimo de modernidad, progresía y cosmopolitismo. Con su apariencia amistosa y alegre y sus limpias líneas, fue uni- versalmente aceptada a la vez por el mundo de los negocios y el mundo del diseño como una fuente casi perfecta para todo. ${ }^{\text {ii }}$

Una de las consecuencias del éxito de la Helvética fue que "se convertiría en la base de la imagen corporativa de numerosas empresas estadounidenses" (Mosley, 2010: 53).

Curiosamente, las tipografías de palo seco son las fuentes que mejores resultados ofrecen en soportes electrónicos, ya que su trazado sencillo no precisa una gran resolución en el dispositivo de salida. Esta cuestión, las ha asociado aún más con los conceptos de tecnología, actualidad y dinamismo.

\section{Tipografía y pantallas}

\subsection{Libros electrónicos $y$ dispositivos de lectura}

Para comenzar, debemos dejar clara la diferencia entre el libro electrónico y los distintos dispositivos que nos permitirán su lectura. Así, entendemos como libro electrónico el monográfico que se publica en formato digital para su lectura en la pantalla de diversos dispositivos electrónicos. Por otra parte, entendemos que en la actualidad los dispositivos que permiten la lectura de textos extensos se pueden organizar en tres categorías: lectores de libros electrónicos (e readers), teléfonos móviles inteligentes (smartphones) y tabletas electrónicas (tablet PC). Excluimos de nuestra selección los ordenadores convencionales (tanto portátiles como de sobremesa) ya que, por tecnología y por hábitos de uso, quedan lejos del resto de dispositivos móviles citados.

De estas tres categorías, la que más atención ha prestado desde su nacimiento a la correcta legibilidad de los textos ha sido, forzosamente, la de los 
lectores de libros electrónicos. Su tecnología, basada en la tinta electrónica, ha permitido desde el origen unas condiciones de reproducción de los textos muy aceptables para tiempos de lectura largos. Además, cuentan con la ventaja, frente a los otros dispositivos móviles de lectura, de que sus pantallas no proyectan luz, sino que necesitan luz procedente del exterior para su lectura. Fornas (2007) explica esta importante característica así:

la luz no se proyecta desde la pantalla, como sucede en la mayoría de los otros aparatos electrónicos, sino que se necesita de la reflexión de la luz externa para poder leer su contenido, igual que sucede con el texto impreso en papel.

Esta cualidad, unida a su alta resolución, permite a estos dispositivos una presentación de los textos muy adecuada para largas sesiones de lectura, ya que se reproducen unas condiciones similares a las del papel.

Sus principales inconvenientes han sido la dificultad para reproducir color y movimiento y la incompatibilidad de los distintos formatos de libros electrónicos existentes en el mercado.

También el precio y la escasa oferta de títulos han lastrado el éxito de estos sistemas. Sin embargo, aunque la industria editorial sigue mostrando sus dudas con respecto a su rentabilidad y a la protección frente al pirateo, su expansión parece estar cada vez más próxima (García, 2011). De hecho, en Estados Unidos, la mitad de los editores consideran que el libro electrónico será el formato dominante en 2014 (Nawotka, 2011).

Además, el precio de los lectores electrónicos está dejando de ser un freno para los usuarios, mientras que el coste de adquisición de obras en formato electrónico se abarata frente a las versiones en papel. También se producen importantes avances en la compatibilidad de formatos y la apuesta de gigantes como Amazon por este mercado hace prever, por fin, el despegue del libro electrónico (Federación de Gremios de Editores, 2011).

Con respecto a smartphones y tablets $p c$, estos dispositivos utilizan una tecnología para sus pantallas diferente a la de los libros electrónicos y muy similar a la de las pantallas de muchos ordenadores portátiles (LEDS). Se trata, en todos los casos, de una tecnología que consigue crear la imagen por medio de luz, lo que ya supone un primer inconveniente importante para la lectura, tal y como hemos señalado. Sin embargo, las grandes mejoras en resolución que han experimentado últimamente hacen que podamos considerarlos como buenos dispositivos de lectura, a pesar de esta limitación. 
Otra gran limitación, en el caso de los smartphones, es el reducido tamaño de sus pantallas. Pero la alta resolución de algunos modelos -la mayor de las disponibles en dispositivos electrónicos- permite que las letras se dibujen con una gran nitidez, por lo que los inconvenientes quedan reducidos a que el número de líneas de texto por pantalla es limitado.

En cualquiera de los dos casos no se trata de dispositivos orientados a la lectura, sino a las comunicaciones multimedia y al entretenimiento. Sin embargo, dentro de su utilización más lúdica, muchos de ellos ofrecen la posibilidad de descargar y almacenar libros electrónicos.

\subsection{Razones históricas para una mala convivencia}

Los ordenadores personales, casi desde su origen, han ofrecido la posibilidad de trabajar con distintos diseños tipográficos. Y ello, quizá porque uno de los padres de esta tecnología, Steve Jobs (2005), asistió en sus años de universitario a un curso de rotulación y caligrafía en el que aprendió sobre la importancia de los distintos elementos tipográficos.

Sin embargo, durante décadas, hemos aceptado que la mayoría de fuentes no eran apropiadas para las pantallas de los ordenadores, porque la baja resolución de estos dispositivos no permitía un dibujo nítido y preciso de cada carácter. En lugar de este dibujo preciso, que sí se obtiene en los procesos de impresión, en las pantallas hemos visto los caracteres con sus contornos suavizados. Este efecto es el denominado antialiasing $\mathrm{y}$, en palabras de Medina (2001: 131):

Es un término que define la técnica consistente en promediar los colores de un objeto y su fondo en una pantalla de ordenador, generando sombras intermedias que evitan los contornos dentados (alisados o rateados) obtenidos de la representación del objeto mediante píxeles.

Por lo tanto, cuantas más curvas y detalles presente una familia tipográfica (como las romanas), más complejo y menos definido será su dibujo en pantalla. Así lo pone de manifiesto también Barth (2008: 36):

Muchas fuentes tipográficas para ordenador son adaptaciones de diseños que pueden tener siglos de antigüedad. Pero a una resolución de sólo 72 ppp, las pantallas de ordenador no tienen la capacidad suficiente para mostrar las fuentes de la mejor forma.

Sin embargo, las familias de trazos constantes y sin remates de ningún tipo (palo seco) serán las que mejor 
definidas aparezcan en los dispositivos electrónicos. Esta realidad contrasta con la tradición en documentos impresos, ya que en el soporte clásico, las romanas ganan la batalla de la legibilidad frente a las palo seco porque sus serifas actúan como conectores entre unos caracteres y otros y ayudan a agrupar letras en palabras de forma más rápida. No obstante, como ya hemos puesto de manifiesto, en las pantallas esta ventaja se pierde y la sencillez del dibujo de las palo seco las hace más legibles.

Precisamente por esta razón en la década de los 90 se comenzaron a diseñar juegos de caracteres específicos para las pantallas de los ordenadores personales. Uno de los casos más emblemáticos en este sentido es el de la Verdana, que nace por la iniciativa de Microsoft de elevar los estándares de calidad de las fuentes para pantallas. De hecho, un estudio sobre legibilidad en pantallas (Bernard et al., 2002) concluía que la tipografía Verdana era la mejor elección para leer en soporte electrónico.

No obstante, en la actualidad se han desarrollado también fuentes romanas especialmente optimizadas para la lectura en pantallas. Según Chaparro, Shaikh y Chaparro (2006) Windows Vista incorporó dos nuevas familias romanas -Cambria y Constantia- especialmente desarrolladas para las pantallas de ordenador.

La limitada universalidad de determinadas fuentes tipográficas también ha sido un freno importante desde el punto de vista de la variedad de diseños en el universo electrónico. Así, en el diseño web siempre se ha optado por fuentes universales, de modo que los diferentes ordenadores de los usuarios dispusieran de ellas. También sucede en el caso del libro electrónico; tal y como nos explica Niño (2012), "el formato $e P U B$ se alimenta de las tipografías incrustadas en la $R A M$ del dispositivo" y "ha de ser compatible con no pocos lectores, ebook, ipad, iphone, móviles"

Estas limitaciones de carácter técnico han provocado, desde nuestro punto de vista, un importante desaprovechamiento de las capacidades simbólicas de la tipografía en el soporte digital.

\subsection{Cuestiones técnicas: tiempo de avances}

Las pantallas de ordenadores y demás dispositivos electrónicos nunca fueron un buen soporte para la lectura de largos textos. Dos limitaciones técnicas las invalidan para ello: su baja resolución (72 o 95 píxeles por pulgada ${ }^{\mathrm{iii}}$ -ppp- frente a los 150 o 300 de la impresión) y su necesidad de usar luz 
para crear las imágenes. La primera cuestión provoca que los caracteres en estos dispositivos aparezcan poco nítidos y la segunda, que los ojos del lector se fatiguen mucho antes que con la lectura en papel. Estos inconvenientes, sin embargo, no son relevantes en la lectura de textos cortos o en el visionado de contenidos multimedia.

La tinta electrónica, centrada en la lectura, resuelve ambas limitaciones a la vez: consigue una resolución de 150 ppp (similar a la de la prensa diaria) y no utiliza luz blanca, sino distintos niveles de gris. Con ello, las letras se definen con nitidez en todos sus rasgos y los ojos no se ven sometidos a la fatiga que provoca la luminosidad.

Estas características hacen a la tinta electrónica la tecnología más apropiada para la lectura de libros y textos extensos en general. Sin embargo, hasta hace poco era imposible reproducir color o imágenes en movimiento, por lo que la utilización de los lectores de libros electrónicos para otros usos lúdicos más multimedia ha estado muy limitada. No obstante, ya a finales de 2009 el fabricante japonés Fujitsu presentó un lector con esta tecnología, capaz de reproducir color (Saínz, 2010).

En cualquier caso, desde el punto de vista de la polivalencia de uso, las tabletas gráficas y los teléfonos inteli- gentes son los dispositivos líderes: sirven para ver películas, para escuchar música, para ojear una revista $\mathrm{y}$, por supuesto, para leer un libro electrónico. Porque las limitaciones técnicas de estos dispositivos han sido superadas. Al menos en lo que se refiere a la resolución. En la actualidad, dispositivos como el iPad 2 ofrecen una resolución de 132 ppp (inferior a la tinta electrónica y a la impresión, pero suficiente para una lectura cómoda), mientras que el iPhone 4 supera en resolución a los sistemas de impresión de calidad, ya que proporciona 326 ppp frente a los 300 de las imprentas.

$¿ \mathrm{Y}$ con respecto a la fatiga provocada por la luz? Este asunto parece tener una solución técnica difícil y ello hace que tengamos que pensar en otras soluciones que van más dirigidas al cambio de hábitos de lectura: estamos habituados a leer negro sobre blanco porque esto nos proporciona el máximo contraste y la mejor legibilidad en papel. Sin embargo, en una pantalla de luz los mejores resultados se obtienen con fondos más oscuros (ya que exigen menos luminosidad y, por lo tanto, fatigan menos) y caracteres más claros. Así pues, las dos limitaciones clásicas para la lectura de textos extensos en pantalla pueden ser superadas fácilmente. Lo que debería permitir, a la vez, utilizar la tipografía en estos nue- 
vos soportes con toda su capacidad gráfica.

\section{4. ¿Ha llegado la tecnología de la reconciliación?}

Actualmente, la resolución ya no supone un problema para la presentación correcta de las distintas familias tipográficas en pantalla. Así pues, el reto tecnológico fundamental para que la tipografía pueda explotarse con todas sus capacidades en los dispositivos electrónicos parece superado.

Sin embargo, en uno de los formatos de archivo que más desarrollo está teniendo en la actualidad para la creación de libros electrónicos, el denominado $e P U B$ (electronic publication), el tratamiento tipográfico que el editor haga será muy poco importante, ya que este formato no guarda la mayoría de estilos tipográficos, porque adapta la composición del texto a las características del dispositivo en el que el libro es mostrado. Cordón, Alonso y Martín (2010: 67) lo explican del siguiente modo:

El formato que comienza a imponerse es ePub, un formato estándar desarrollado por IDPF (International Digital Publishing Forum). Su pretensión es la de alcanzar la capacidad de mostrar un texto en cualquier pantalla, independiente- mente de sus dimensiones y sistema, permitiendo que sea el usuario quien controle la presentación: tamaño de letra, tipografía, etc. según el software empleado.

De este modo, cada usuario puede elegir la tipografía, la composición de párrafo o incluso la interlínea que prefiera, ya que la única limitación se la impondrá su dispositivo de lectura. El editor del libro, al generar el archivo $e P U B$, sólo podrá demandar del dispositivo de lectura una fuente "original" de amplia difusión y libre de derechos (como, por ejemplo, la Times) o la fuente que, por defecto, el dispositivo incorpore para esa categoría tipográfica (por ejemplo, Romanas). No obstante, cabe señalar que atributos como las mayúsculas, la negrita o la cursiva sí se conservan.

Esta limitación puede provocar pérdidas importantes de información, sobre todo en aquellos textos en los que la composición tipográfica es necesaria para comprender el relato. Tomamos prestados dos ejemplos extraídos de un artículo de Nørgaard sobre semiótica tipográfica (2009) en los que se pone en evidencia la importancia de la composición tipográfica en una novela: en primer lugar, recordamos la obra de Michael Ende, La historia interminable (1979), en la que los textos se alternan en rojo y verde, en función de la 
narración. O la más reciente y exitosa novela de Dan Brown El código Da Vinci (2003), en la que un cambio en la familia tipográfica nos indica que determinados textos son el resultado de búsquedas en Internet.

No obstante, parece que frente a la multitud de formatos nativos reinante hace poco tiempo, el archivo $e P U B$, cuya principal baza es precisamente la compatibilidad con los distintos lectores electrónicos, gana terreno incluso sobre otro formato de archivo universal: el $P D F$. La ventaja tomada por el $e P U B$ es lógica, puesto que, al adaptar la composición del texto al tamaño de la pantalla de cada dispositivo, la lectura resulta mucho más cómoda que en los archivos $P D F$, en los que composición y formato son fijos, con independencia de la pantalla. Así pues, mientras que el formato $P D F$ conserva todos los atributos tipográficos con los que es editado, en muchos casos obligará al lector a utilizar el zoom de su dispositivo para acercarse al documento y navegar a lo ancho de la página.

\section{Caso de estudio: La historia interminable $y$ el sony reader $P R S-T 1$}

\subsection{Justificación}

Podríamos afirmar que La Historia Interminable (Michael Ende, 1979) es un libro dentro de otro libro. Así, este clásico de la literatura juvenil narra dos historias paralelas que acaban uniéndose en una única aventura fantástica. Gracias a esta particularidad narrativa, a lo largo del relato, el tratamiento tipográfico del texto tiene un valor muy importante, ya que nos permite diferenciar una historia de la otra. Precisamente esta característica es la que nos ha hecho seleccionar este texto para nuestro análisis de contenido, ya que aquí el tratamiento tipográ- fico del relato es especialmente relevante y va más allá de las cuestiones básicas vinculadas a la legibilidad.

Por otra parte, el formato de archivo elegido es el $e P U B^{i v}$, el más popular para libros electrónicos en la actualidad. Con respecto al lector electrónico, se ha optado por el Sony Reader PRS$T 1$ por las siguientes razones. En primer lugar, se trata de un aparato equipado con tecnología de tinta electrónica, la más apropiada, como ya hemos puesto de manifiesto, para la lectura prolongada frente a otros dispositivos de leds. Además, el lector de Sony es considerado como uno de los más cómodos por la calidad de su pantalla, su 
usabilidad y su reducido peso (Alamo, 2012).

\subsection{Análisis comparativo}

Para la comparación de las dos ediciones, se ha elaborado una tabla en la que se han recogido datos como las categorías tipográficas a las que pertenecen las fuentes utilizadas, los colores, las variaciones sobre dichas fuentes (cursivas, negritas, etc.) o el tipo de justificación y sangrado utilizado en cada caso. Obsérvese que la familia tipográfica no se considera una variable relevante, ya que en el formato $e P U B$ el editor sólo puede determinar la categoría tipográfica, ya que la fuente concreta dependerá de las instaladas en cada dispositivo de lectura. En cualquier caso, desde el punto de vista de nuestra investigación, es suficiente con reconocer la categoría, ya que el catálogo de simbolismo tipográfico se ha elaborado atendiendo a categorías, y no a familias concretas.

Para facilitar la comparación de estilos tipográficos, hemos dividido el análisis en dos partes, que corresponden con los dos relatos que se simultanean en la novela.
Cuadro $n^{o}$ 1. Análisis comparativo

\begin{tabular}{|c|c|c|c|c|}
\hline & \multicolumn{2}{|c|}{ Relato I } & \multicolumn{2}{|c|}{ Relato II } \\
\hline & ePUB & Papel & ePUB & Papel \\
\hline $\begin{array}{l}\text { Categoría } \\
\text { tipográfica }\end{array}$ & $\begin{array}{l}\text { Palo } \\
\text { seco }\end{array}$ & Romana & Romana & Romana \\
\hline Color & Negro & Rojo & Negro & Verde \\
\hline Variaciones & No & Sí & Sí & Sí \\
\hline Sangrado & Sí & No & No & No \\
\hline Adornos & No & Sí & No & Sí \\
\hline Capitulares & Sí & Sí & Sí & Sí \\
\hline Otros & Sí & Sí & Sí & Sí \\
\hline
\end{tabular}

Fuente: elaboración propia

3.2.1. Categoría

tipográfica, color

\section{y sangrado}

La edición en papel utiliza una sola familia tipográfica, de la categoría de las romanas antiguas, mientras que en la edición electrónica, si no se personaliza la tipografía, los textos están compuestos en dos familias diferentes, una de ellas romana antigua y la otra de palo seco. Esta distinción permite, en el $e P U B$, diferenciar el relato I del relato II, mientras que en la edición de papel esa diferenciación se hace mediante un cambio en el color del texto (sin modificar la tipografía), de modo que el relato I está en color rojo y el relato II en verde.

Con respecto al uso del color, los dispositivos de tinta electrónica capaces de reproducirlo son -en la actualidadescasos y caros. Sin embargo, la tecnología actual (E-Ink Pearl) sí es capaz de reproducir 16 niveles de gris dife- 
rentes, que son los que se usan para reproducir imágenes en esa reducida escala de grises. Esto quiere decir que la versión electrónica de La Historia Interminable también podría haber recurrido a un cambio de nivel de gris para diferenciar los dos relatos. Sin embargo, parece que esta tecnología va desarrollando un lenguaje tipográfico propio que va más allá de la mera imitación de la edición en papel.

A ese lenguaje propio del libro electrónico parece deberse también otro recurso para diferenciar los dos relatos cuando se personaliza la tipografía recordemos que esta es una de las principales peculiaridades del ereader - y se pierde, por tanto, la configuración original. Nos referimos al sangrado de párrafo, que se convierte en la única característica tipográfica estable en la versión electrónica cuando se opta por cambiar las tipografías originales.

\subsubsection{Adornos, capitulares y otros recursos}

En la edición en papel con la que hemos trabajado, el número de página se sitúa en la parte central de la cabecera de cada página y va flanqueado por dos adornos florales que se extienden de margen a margen. Este recurso decorativo y narrativo (pues ayuda a recrear el universo fantástico y natural en el que se desarrolla la mayor parte de la novela) no se da en la edición electrónica, por razones de carácter técnicov .

Sin embargo, las capitulares góticas acompañadas de ilustraciones de Roswitha Quadflieg que identifican el comienzo de cada capítulo sí que se reproducen en la versión electrónica del libro, proporcionando ese valor narrativo al que hemos aludido con anterioridad.

Por otros recursos entendemos aquellos detalles gráficos y compositivos que tienen un valor importante en la narración, como la composición en negativo y enmarcada con la que se inicia el prólogo de la novela (y que representa lo que ve el protagonista del libro a través del cristal). Este elemento, presente en la edición de papel en color rojo, aparece también en el libro electrónico, aunque en color negro, como ya se ha puesto de manifiesto.

La tipografía gótica aparece no solo en las letras capitulares, sino que también se utiliza para componer el título del libro que el protagonista lee en la novela. Y ello ocurre tanto en la edición en papel como en la edición electrónica, si bien en este segundo caso el texto está incorporado como una imagen en mapa de bits (no como una tipografía). Ello es posible ya que se trata de un texto corto, que aparece 
solo en un par de ocasiones, por lo que el tiempo para cargar la página y el peso del archivo no se ven afectados.

\section{Conclusiones}

Los últimos avances tecnológicos en lo que respecta a la resolución de las pantallas hacen que, por primera vez, el soporte electrónico pueda considerarse seriamente como una alternativa a la lectura de textos largos frente al papel.

Esta mejora de la resolución, además, permite que todas las familias tipográficas, incluso aquellas con alta modulación y detalles muy finos, se puedan reproducir con nitidez en pantallas, por lo que las posibilidades de explotar el simbolismo de la tipografía en soporte electrónico podrían ser iguales a las del papel.

Sin embargo, el formato $e P U B$, uno de los más extendidos actualmente para guardar libros electrónicos, no conserva características tipográficas tan importantes como la familia seleccionada por el editor. Precisamente esta característica es la que lo dota de una gran universalidad. Pero provoca, a la vez, que cada usuario, en función de las posibilidades de su lector electrónico, pueda seleccionar la familia tipográfica, el tipo de párrafo o la interlínea que prefiera.
Por lo tanto, el formato de archivo $P D F$ sería preferible al $e P U B$ si pretendemos conservar la capacidad simbólica de la tipografía y de la composición de textos. Sin embargo, su incapacidad para ajustar la longitud de las líneas a los distintos dispositivos de lectura lo hacen, a igualdad de compatibilidad, menos competitivo que el $e P U B$, en el que el peso de la composición tipográfica en general es mucho menor.

Así pues, el formato $e P U B$ solamente conserva los atributos tipográficos referidos a las variaciones tipográficas (mayúsculas, cursiva y negrita), al sangrado de párrafo y a la categoría de tipos (romanas o palo seco generalmente).

Ante esta situación podemos concluir que, si bien se han producido importantes mejoras tecnológicas en lo que respecta a la resolución de las pantallas, para que la tipografía pueda ser explotada en sus cotas máximas aún deben resolverse muchas cuestiones relacionadas con los formatos de archivo en los que los libros electrónicos son generados. Además, la dificultad para incorporar tipografías protegidas 
por derechos de autor en los dispositivos de lectura limita aún más su utilización, de modo que, en la actualidad, las opciones son muy reducidas.

Ante la pregunta que nos planteamos al comienzo de esta investigación (¿Los textos electrónicos, en la actualidad, aprovechan el simbolismo tipográfico de una forma tan amplia como los impresos?) queremos destacar que el libro electrónico está desarrollando su propio lenguaje tipográfico, aprovechando sus ventajas (sencillez para combinar distintas categorías tipográficas a partir de unas pocas familias cargadas en la memoria) y teniendo en cuenta sus limitaciones (imposibilidad de reproducir color). Así pues, no se trata tanto de observar si las ediciones electrónicas pueden imitar el simbolismo tipográfico de las ediciones en papel, sino de prestar atención a la aparición de una nueva forma de expresión tipográfica, limitada aún por condicionantes técnicos.

Para concluir, debemos poner de manifiesto, una vez más, que las limitaciones tecnológicas no deben hacernos renunciar a las capacidades retóricas de la tipografía, aunque estas capacidades tengan que desarrollarse de formas nuevas.

\section{Referencias}

ALAMO, Alfredo (2012, 6 de febrero). Sony PRS-T1. Lo hemos probado. Lecturalia.com. Recuperado de http://www.lecturalia.com/blog/2012/02/ 06/sony-prs-t1-lo-hemos-probado

BARTH, Steve (2008). Digital Designs. EContent Magazine, 31(1), 32-36.

BERNARD, Michael, LIDA, Bonnie, RILEY, Shannon, HACKLER, Telia y JANZEN, Karen (2002). A comparison of popular online fonts: Which size and type is best. Usability News, 4(1). Recuperado de http://www.surl.org/usabilitynews

/41/onlinetext.asp

CHAPARRO, Barbara, DAWN SHAIKH, A. y CHAPARRO, Alex (2006). Examining the Legibility of Two New ClearType Fonts. Usability News, 8(1). Recuperado de http://www.surl.org/ usabilitynews/81/legibility.asp
CORDÓN, José Antonio, ALONSO, Julio y MARTÍN, Helena (2010). Los libros electrónicos: la tercera ola de la revolución digital. Anales de documentación,13, 53-80.

SAÍNZ, Rosa Ma (Cord.) (2010). El futuro de las publicaciones electrónicas. Madrid y Barcelona: Fundación Telefónica y Ariel.

GAMONAL, Roberto (2005). Tipo/retórica: una aproximación a la retórica tipográfica. Icono $14,5$.

FORNAS, Ricardo (2007, 3 de mayo). El libro electrónico. El País. Recuperado de http://elpais.com/diario/2007/05/03/ciberpais/1 178156423_850215.html

GARCÍA, Juan Manuel (2011, 22 de febrero). El mercado del eBook creció un $200 \%$ en 2010 y despegará en España este año, según los expertos. La Vanguardia. Recuperado de http://www.lavanguardia.com/enlaces-deldia/20110222/54119355241/el-mercado-del- 
ebook-crecio-un-200-en-2010-y-despegara-enespana-este-ano-segun-los-expertos.html

GÜRTLER, André (2005). Historia del periódico y su evolución tipográfica. Valencia: Campgràfic.

JOBS, Seteve (2005) Discurso de clausura del año académico 2005 en la Universidad de Stanford. Recuperado de http://news.stanford.edu/news/ 2005/june15/jobs-061505.html

LOXLEY, Simon (2007). La historia secreta de las letras. Valencia: Campgràfic.

MARTÍN MONTESINOS, José Luis y MAS HURTANA, Montse (2001). Manual de Tipografía. Valencia: Campgràfic.

MARTÍNEZ VAL, Juan (2002). Tipografía práctica. Usos, normas, tecnologías y diseños tipográficos en los inicios del siglo XXI. Madrid: Laberinto comunicación.

MEDINA, Jorge Miguel (2001). Tipografía digital, Madrid: Anaya Multimedia.

MOSLEY, James (2010). Sobre los orígenes de la tipografía moderna. Valencia: Campgràfic.

NAWOTKA, Edgard (2011, 26 de enero). Bold Predictions: Half of US Publishers Expect Ebooks to Be Dominant Format by 2014.

Publishingperspectives.com. Recuperado de http://publishingperspectives.com/2011/01/half -of-us-publishers-expect-e-books-to-be-

dominant-by-2014/
FEDERACIÓN de GREMIOS de EDITORES de ESPAÑA (2011). $2^{a}$ Encuesta sobre el libro digital en España. Recuperado de http://www.mcu.es/libro/docs/MC/Observatori o/pdf/encuesta_libro_digital_2011.pdf

NIÑO, José (2012), Entrevista personal. Gerente de J. A. Diseño Editorial, S. L. Empresa encargada del diseño editorial, tanto en papel como electrónico, de algunas colecciones de la editorial Planeta.

NØRGAARD, Nina (2009). The Semiotics of Typography in Literary Texts. A multimodal approach. Orbis Litterarum, 64(2), 141-160. doi: 10.1111/j.1600-0730.2008.00949.x

MOSLEY, James (2010). Sobre los orígenes de la tipografía moderna. Valencia: Campgràfic.

SOLOMON, Martin (1988). El arte de la tipografía. Introducción a la tipo.icono.grafía. El diseño tipográfico actual a través de la tipografía clásica. Madrid: Tellus.

VANDERBILT, Tom (2004, 20 de febrero). Courier, dispatched. Slate.com. Recuperado de http://www.slate.com/articles/business_and_tec h/design/2004/02/courier_dispatched.html

WILLBERG, Hans Peter y FORSSMAN, Friedrich (2002). Primeros auxilios en tipografía. Consejos para diseñar con tipos de letra. Barcelona: Gustavo Gili.

Cita de este artículo

Subiela Hernández, B. J. (2012) El simbolismo tipográ-

fico en los nuevos dispositivos móviles: hacia

la reconciliación de letras y pantallas. Icono14 10(2),

126-147, doi: $\underline{10.7195 / r i 14 . v 10 i 2.146}$ 


\section{NOTAS}

iPara establecer estas categorías partiremos de la clasificaión Vox-ATypI de 1964, una de las clasificaciones tipográficas basadas en rasgos morfológicos más utilizadas y extendidas en la actualidad.

${ }^{i i}$ Publicado originalmente en inglés (la traducción es propia): "became synonymous with modern, progressive, cosmopolitan attitudes. With its friendly, cheerful appearance and clean lines, it was universally embraced for a time by both the corporate and design worlds as a nearly perfect typeface to be used for anything and everything".

iii 72 ppp para dispositivos Apple y 95 para PC

${ }^{\text {iv }}$ Ha resultado completamente imposible adquirir la versión digital de La Historia Interminable de forma legal, ya que editores y libreros sólo ofrecen libros electrónicos de novedades editoriales.

${ }^{\mathrm{v}}$ Las páginas en la edición electrónica tienen una extensión variable, en función de la tipografía y del cuerpo que el usuario seleccione, por lo que estos elementos no podrían, de ningún modo, formar parte del texto. 